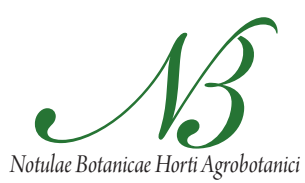

Cluj-Napoca

\title{
Sodium Chloride Stress Induced Changes in Leaf Osmotic Adjustment of Trifoliate Orange (Poncirus trifoliata) Seedlings Inoculated with Mycorrhizal Fungi
}

\author{
Ying-Ning $\mathrm{ZOU}^{1}$, Qiang-Sheng $\mathrm{WU}^{1,2 *}$ \\ ${ }^{1}$ Yangtze University, College of Horticulture and Gardening, Jingzhou, Hubei 434025, People's \\ Republic of China; wuqiangsh@163.com (*0rresponding author) \\ ${ }^{2}$ South China Agricultural University, Key Laboratory of Ecological Agriculture of Ministry \\ of Agriculture, Guangzhou 510642, People's Republic of China
}

\begin{abstract}
Citrus plants are sensitive to salinity, and thus employing new approaches to alleviate salt damage are necessary. The present study evaluated the effect of two arbuscular mycorrhizal fungi (AMF), Glomus mosseae and G. versiforme, on leaf osmotic adjustment of trifoliate orange (Poncirus trifoliata) seedings exposed to $100 \mathrm{mM} \mathrm{NaCl}$. Salinity significantly inhibited mycorrhizal colonization, plant biomass and leaf relative water content, whereas the reduce of plant biomass was notably alleviated by the mycorrhizal colonization. Mycorrhizal seedlings exhibited significantly lower $\mathrm{Na}^{+}$and $\mathrm{Ca}^{2+}$ concentrations, whilst also recorded higher $\mathrm{K}^{+}$concentration and $\mathrm{K}^{+} / \mathrm{Na}^{+}, \mathrm{Ca}^{2+} / \mathrm{Na}^{+}$ and $\mathrm{Mg}^{2+} / \mathrm{Na}^{+}$ratios at both salinity levels. Under salinity stress, mycorrhizal symbiosis markedly decreased sucrose concentrations of leaves and also increased glucose, fructose and proline concentrations of leaves. The results suggest that arbuscular mycorrhizas improved leaf osmotic adjustment responses of the seedlings to salt stress, thus enhancing salt tolerance of mycorrhizal plants.
\end{abstract}

Keywords: arbuscular mycorrhizal fungi, citrus, Glomus mosseae, osmotic adjustment, salt stress, trifoliate orange

\section{Introduction}

Soil salinity is an important abiotic stress, which strongly affects crop productivity by way of accumulation of toxic $\mathrm{Na}^{+}$and $\mathrm{Cl}^{-}$ions and nutrient imbalance (Chinnusamy et al., 2005; Sairam and Tyagi, 2004). Until now, $>6 \%$ of the world's land and $30 \%$ of the world's irrigated areas have been adversely affected by soil salinity (Chaves et al., 2009). Citrus, the second economically cultivated fruit tree in China, is relatively sensitive to salinity stress (Levy and Syvertsen, 2004). Soil salinity not only leads to the deleterious effects on citrus growth and fruit yield but also restricts citrus cultivation in south saline regions of China. Therefore, enhancing salt tolerance of citrus plants will probably be one of the important objectives.

The excess of salt is able to cause osmotic stress by way of the decrease of soil water potential, thus disturbing plant water relation (de Lacerda et al., 2003). Osmotic adjustment, a net increase in intracellular inorganic and/or organic solutes, can maintain turgor and reduce the deleterious effects of salt stress on plants (Hajlaoui et al., 2010; de Lacerda et al., 2003). These intracellular solutes include $\mathrm{K}^{+}, \mathrm{Ca}^{2+}, \mathrm{Mg}^{2+}$, proline, glycine betaine, free amino acids, sugars, polyamines, polyphenols, etc. The response of the solute concentrations to salinity is regarded as a fundamental aspect of salinity tolerance (Reed, 1989). Citrus plants can improve osmotic adjustment for altering salt tolerance (Pérez-Pérez et al., 2009). In Atriplex nummularia, roots and leaves displayed contrary osmotic adjustment mechanisms in response to $\mathrm{NaCl}$ stress: an efficient osmotic adjustment only in leaves but not roots (Silveira et al., 2009).

Arbuscular mycorrhiza (AM), a mutualistic association between roots of plants and soil arbuscular mycorrhizal fungi (AMF), provides the hosts with essential nutrients and water from soils (Requena et al., 2007). In return, $\sim 20 \%$ of plant photosynthetic carbon is transported into the root endosymbiotic fungi to maintain their growth. It is well documented that AMF colonization can alleviate damage of host plants caused by soil salinization through osmotic adjustment (Evelin et al., 2009). Compared with non-mycorrhizal corresponding plants, the $\mathrm{NaCl}$-stressed maize (Zea mays) plants colonized by Glomus mosseae exhibited higher soluble sugars and electrolyte concentrations, suggesting the higher osmoregulation capacity of these plants (Feng et al., 2002). A field experiment also showed that the reduction in $\mathrm{Na}$ uptake together with a concomitant increase in $\mathrm{Mg}$ absorption in G. macrocarpum-colonized Sesbania aegyptiaca and $S$. grandiflora plants may be important salt-alleviating mechanisms for plants grown in saline soil (Giri and Mukerji, 2004). However, there are two different effects of AMF on citrus plants. G. mosseae and Paraglomus occultum significantly increased the $\mathrm{K}^{+} / \mathrm{Na}^{+}$ratio in the $\mathrm{NaCl}$-stressed 
Citrus tangerine seedlings (Wu et al., 2010b). Mycorrhizal colonization also reduced the proline concentrations of Carrizo citrange, irrespective of salinity level (Duke et al., 1986). However, Graham and Syvertsen (1989) observed the increase of $\mathrm{Cl}^{-}$concentrations in leaves and roots of salinized sweet orange and sour orange. Murkute et al. (2006) reported no significantly physiological effects on salt-stressed citrus rootstocks by AMF inoculation.

The objective of the present study was to evaluate the effects of two Glomus species on inorganic $\left(\mathrm{Na}^{+}, \mathrm{K}^{+}, \mathrm{Ca}^{2+}\right.$ and $\mathrm{Mg}^{2+}$ ) and organic (proline and sugars) solutes of citrus seedlings exposed to salt stress.

\section{Materials and methods}

\section{Experimental design}

The experiment was laid out in a completely randomized block design with two factors in four replications. The first factor was mycorrhization in three levels, including inoculation with G. mosseae, G. versiforme and non-AMF. The second factor was salinization in two levels, including 0 and $100 \mathrm{mM} \mathrm{NaCl}$ concentrations, which are based on the results conducted by Pérez-Tornero et al. (2009) in $C$. macrophylla grown in $0 \sim 150 \mathrm{mM} \mathrm{NaCl}$ and Ferreira and Lima-Costa (2008) in Citrus cv. 'Carvalhal' tangor grown in $100 \mathrm{mM} \mathrm{NaCl}$. Each treatment had three replicates for a total of 18 pots.

\section{Plant culture}

The trifoliate orange [Poncirus trifoliata (L.) Raf.)] seedlings germinated at $25^{\circ} \mathrm{C}$ for 7 days were transferred into the plastic pots $(18 \mathrm{~cm}$ in depth and $20 \mathrm{~cm}$ in mouth diameter) containing $3.4 \mathrm{~kg}$ of autoclaved soil, vermiculite, and sphagnum mixture $(5 / 2 / 1, v / v / v)$. Fifteen gram mycorrhizal inocula of $G$. mosseae and G. versiforme containing fungal spores, infected maize roots, and growth substrate was inoculated into the pots before transplanting. The non-AMF control received the same autoclaved inoculum. The inoculumn was supplied by the Institute of
Plant Nutrition and Resources, Beijing Academy of Agriculture and Forestry Sciences.

The salt treatments began at 90 days of acclimation. Half of AMF and non-AMF seedlings was randomly used as the non-salt treatment, and the other as salt-stressed treatment. The salt-stressed treatment was applied by 100 $\mathrm{mM} \mathrm{NaCl}$ solution stepwisely using $25 \mathrm{mM} \mathrm{NaCl}$ per day to avoid osmotic shock, whilst the non-salt treatment received $0 \mathrm{mM} \mathrm{NaCl}$ solution as the control. The plants were randomly placed in a plastic greenhouse (Jingzhou, China) without any temperature equipments from March to August 2009.

\section{Parameter measurements}

The experiment was ended after 7 weeks of salt treatments, and the shoots and roots were separated. The AM structures were stained with trypan blue method described by Phillips and Hayman (1970), and the AM colonization was quantified by Wu et al. (2008).

Leaf relative water content (RWC) was determined by the method of Wu and Xia (2006). The proline concentration was determined according to the method of Troll and Lindsley (1955). The sucrose, glucose and fructose concentrations were carried out following Wu et al. (2010a).

The $\mathrm{K}^{+}, \mathrm{Na}^{+}, \mathrm{Mg}^{2+}$ and $\mathrm{Ca}^{2+}$ concentrations were determined directly using an Atomic Absorption Spectrometer (AI 1200, Aurora Instruments Limited, Canada).

\section{Statistical analysis}

The data were analyzed by two-factor ANOVA with SAS v 8.1. Fisher's protected least significant difference (LSD, $P<0.05$ ) was used to compare the significant differences between treatments and interactions.

\section{Results}

The present research did not observe mycorrhizal colonization in un-inoculated seedlings growing under 0 and $100 \mathrm{mM} \mathrm{NaCl}$ conditions (Tab. 1). Mycorrhizal coloniza-

Tab. 1. Arbuscular mycorrhizal colonization and biomass of mycorrhizal and non-mycorrhizal trifoliate orange (Poncirus trifoliata) seedlings under salt stress

\begin{tabular}{|c|c|c|c|c|c|}
\hline \multirow{2}{*}{$\mathrm{NaCl}(\mathrm{mM})$} & \multirow{2}{*}{ Mycorrhizal status } & \multirow{2}{*}{$\begin{array}{c}\text { AM colonization } \\
(\%)\end{array}$} & \multicolumn{3}{|c|}{ Dry weight $\left(\mathrm{g} \mathrm{plant}^{-1}\right)$} \\
\hline & & & Shoot & Root & Plant \\
\hline \multirow[t]{3}{*}{0} & G. versiforme & $65.31 \mathrm{c}$ & $0.37 \mathrm{ab}$ & $0.12 b$ & $0.49 \mathrm{~b}$ \\
\hline & G.mosseae & $75.69 \mathrm{a}$ & $0.42 \mathrm{a}$ & $0.17 \mathrm{a}$ & $0.59 \mathrm{a}$ \\
\hline & Non-AMF & $0 \mathrm{e}$ & $0.31 \mathrm{~cd}$ & $0.09 \mathrm{c}$ & $0.40 \mathrm{c}$ \\
\hline \multirow[t]{3}{*}{100} & G. versiforme & $59.52 \mathrm{~d}$ & $0.33 \mathrm{bc}$ & $0.09 \mathrm{c}$ & $0.42 \mathrm{c}$ \\
\hline & G.mosseae & $67.76 \mathrm{~b}$ & $0.38 \mathrm{a}$ & $0.11 b c$ & $0.49 \mathrm{~b}$ \\
\hline & Non-AMF & $0 \mathrm{e}$ & $0.26 \mathrm{~d}$ & $0.07 \mathrm{~d}$ & $0.33 \mathrm{~d}$ \\
\hline \multicolumn{6}{|l|}{ ANOVA } \\
\hline Salt stress & & ** & * & ** & ** \\
\hline AMF & & $* *$ & ** & ** & ** \\
\hline Interaction & & ** & NS & * & NS \\
\hline
\end{tabular}

Note: Same letter within each column indicates no significant difference among treatments $(P<0.05)$. NS, no significant. ${ }^{*}, P<0.05$. $^{* *}, P<0.01$ 
66

tion of inoculated seedlings ranged from 59.52 to $75.69 \%$, and salt stress significantly decreased mycorrhizal colonization. G. mosseae-colonization was markedly higher than G. versiforme-colonization, regardless of the salt levels.

Analysis of dry biomass showed that all the dry weights decreased with the increasing $\mathrm{NaCl}$ concentrations ( Tab. 1). There were significant differences between mycorrhizal and non-mycorrhizal seedlings. Generally, the inoculated seedlings under salt stress conditions recorded significantly higher shoot, root and plant dry weights compared to the un-inoculated ones. Moreover, the significant differences were more obvious in $G$. mosseae-colonized seedlings.

Leaf RWC reduced with the increasing salinity, and the different significances were among mycorrhizal seedlings but not non-mycorrhizal seedlings (Fig. 1). Under the non-salinity stress conditions, the two AMF significantly increased leaf RWC compared to non-AMF treatment. Moreover, G. mosseae-inoculation recorded notably higher effects on leaf RWC than $G$. versiforme-inoculation. Under salinity stress conditions, G. mosseae but not G. versiforme markedly increased leaf RWC as compared to non-AMF seedlings.

For ionic concentrations, soil salinity reduced $\mathrm{K}^{+}$concentration but increased $\mathrm{Na}^{+}$and $\mathrm{Ca}^{2+}$ concentrations in leaves of both AMF and non-AMF seedlings compared to non-salinity stress conditions (Tab. 2). $\mathrm{Na}^{+}$concentration was always lower in AMF than in non-AMF seedlings, and G. mosseae-colonized seedlings exhibited lower $\mathrm{Na}^{+}$concentration than $G$. versiforme-colonized seedlings under $100 \mathrm{mM} \mathrm{NaCl}$ but not $0 \mathrm{mM} \mathrm{NaCl}$ conditions. $\mathrm{K}^{+}$concentration was notably enhanced by AMF inoculation, whilst the significant differences were not observed the mycorrhizal seedlings. In leaves, AMF plants had lower $\mathrm{Ca}^{2+}$ concentration than non-AMF plants regardless of soil salinization, and the significant differences were not observed between the mycorrhizal seedlings. Mycorrhizal seedlings under non-salinity stress recorded lower $\mathrm{Mg}^{2+}$ concentrations of leaves as compared to non-mycorrhizal seedlings; under salinity stress, only $G$. versiforme-colonized seedlings maintained higher $\mathrm{Mg}^{2+}$ concentrations of leaves.

Tab. 2. Effects of salinity and mycorrhizal inoculation on ionic concentrations and ionic balance in leaves of trifoliate orange (Poncirus trifoliata) seedlings

\begin{tabular}{|c|c|c|c|c|c|c|c|c|}
\hline \multirow{2}{*}{$\mathrm{NaCl}(\mathrm{mM})$} & \multirow{2}{*}{$\begin{array}{c}\text { Mycorrhizal } \\
\text { status }\end{array}$} & \multicolumn{4}{|c|}{ Ionic concentration $\left(\mathrm{mg} \mathrm{g}^{-1}\right)$} & \multicolumn{3}{|c|}{ Ionic balance } \\
\hline & & $\mathrm{Na}^{+}$ & $\mathrm{K}^{+}$ & $\mathrm{Ca}^{2+}$ & $\mathrm{Mg}^{2+}$ & $\mathrm{K}^{+} / \mathrm{Na}^{+}$ & $\mathrm{Ca}^{2+} / \mathrm{Na}^{+}$ & $\mathrm{Mg}^{2+} / \mathrm{Na}^{+}$ \\
\hline \multirow[t]{3}{*}{0} & G. versiforme & $4.27 \mathrm{e}$ & $41.05 \mathrm{ab}$ & $18.77 \mathrm{~d}$ & $8.39 \mathrm{c}$ & $9.65 \mathrm{~b}$ & $4.41 \mathrm{a}$ & $1.97 \mathrm{~b}$ \\
\hline & G.mosseae & $4.17 \mathrm{e}$ & $43.46 \mathrm{a}$ & $18.30 \mathrm{~d}$ & $9.20 \mathrm{~b}$ & $10.44 a$ & $4.39 \mathrm{a}$ & $2.21 \mathrm{a}$ \\
\hline & Non-AMF & $6.91 \mathrm{~d}$ & $38.26 \mathrm{~cd}$ & $24.89 \mathrm{c}$ & $10.82 \mathrm{a}$ & $5.57 \mathrm{c}$ & $3.61 \mathrm{~b}$ & $1.57 \mathrm{c}$ \\
\hline \multirow[t]{3}{*}{100} & G. versiforme & $12.06 \mathrm{~b}$ & $40.46 \mathrm{bc}$ & $25.98 \mathrm{bc}$ & $9.84 \mathrm{~b}$ & $3.37 \mathrm{~d}$ & $2.15 \mathrm{~d}$ & $0.82 \mathrm{~d}$ \\
\hline & G.mosseae & $10.97 \mathrm{c}$ & $39.00 \mathrm{bc}$ & $27.68 \mathrm{ab}$ & $8.29 \mathrm{c}$ & $3.56 \mathrm{~d}$ & $2.52 \mathrm{c}$ & $0.76 \mathrm{~d}$ \\
\hline & Non-AMF & $14.20 \mathrm{a}$ & $35.87 \mathrm{~d}$ & $28.84 \mathrm{a}$ & $8.31 \mathrm{c}$ & $2.53 \mathrm{e}$ & $2.03 \mathrm{~d}$ & $0.59 \mathrm{e}$ \\
\hline \multicolumn{9}{|l|}{ ANOVA } \\
\hline Salt stress & & ** & ** & ** & ** & ** & ** & ** \\
\hline AMF & & ** & ** & ** & $*$ & ** & ** & ** \\
\hline Interaction & & NS & NS & * & ** & ** & * & ** \\
\hline
\end{tabular}

Note: Same letter within each column indicates no significant difference among treatments $(P<0.05)$. NS, no significant. ${ }^{*}, P<0.05{ }^{* *}, P<0.01$

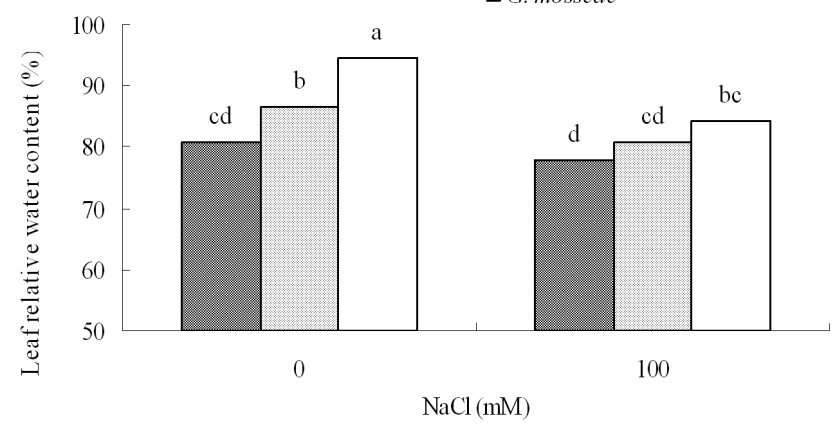

Fig. 1. Effect of salinity and mycorrhizal inoculation on leaf relative water content of trifoliate orange (Poncirus trifoliata) seedlings

For ionic balance, salt stress markedly reduced the ratio of $\mathrm{K}^{+} / \mathrm{Na}^{+}, \mathrm{Ca}^{2+} / \mathrm{Na}^{+}$or $\mathrm{Mg}^{2+} / \mathrm{Na}^{+}$(Tab. 2). The AMF seedlings had higher $\mathrm{K}^{+} / \mathrm{Na}^{+}, \mathrm{Ca}^{2+} / \mathrm{Na}^{+}$and $\mathrm{Mg}^{2+} / \mathrm{Na}^{+}$ ratios than the non-AMF control seedlings at both salinity levels. Herein, under the non-salinity stress, compared to $G$.versiforme-colonized seedlings, $G$. mosseae-colonized seedlings recorded significantly higher $\mathrm{K}^{+} / \mathrm{Na}^{+}$and $\mathrm{Mg}^{2+} /$ $\mathrm{Na}^{+}$ratios. Similar response was observed in the ratio of $\mathrm{Ca}^{2+} / \mathrm{Na}^{+}$between $G$.versiforme and $G$. mosseae-colonized seedlings.

In the two fungal species, only $G$. mosseae significantly increased sucrose concentrations of leaves under non-salinity stress (Tab. 3). However, under salinity stress, the two AMF markedly decreased sucrose concentrations of leaves. The seedlings inoculated with AMF had higher concentrations of glucose and fructose when grown with 0 and $100 \mathrm{mM} \mathrm{NaCl}$ (Tab. 3). Though proline concentration increased with the increasing salinity, no significant differences were observed. Compared to the non-AMF control seedlings, proline concentration was increased by 36 and $43 \%$ in $G$. versiforme and $G$. mosseae-colonized seedlings under the non-salinity stress, respectively; Under the salinity stress, $G$. versiforme and $G$. mosseae-colonized seedlings by 45 and $67 \%$, respectively. 
Tab. 3. Effect of salinity and mycorrhizal inoculation on organic solute concentrations in leaves of trifoliate orange (Poncirus trifoliata) seedlings

\begin{tabular}{|c|c|c|c|c|c|}
\hline $\mathrm{NaCl}(\mathrm{mM})$ & $\begin{array}{c}\text { Mycorrhizal } \\
\text { status }\end{array}$ & $\begin{array}{l}\text { Sucrose } \\
\left(\mathrm{mg} \mathrm{g}^{-1}\right)\end{array}$ & $\begin{array}{l}\text { Glucose } \\
\left(\mathrm{mg} \mathrm{g}^{-1}\right)\end{array}$ & $\begin{array}{c}\text { Fructose } \\
\left(\mathrm{mg} \mathrm{g}^{-1}\right)\end{array}$ & $\begin{array}{l}\text { Proline } \\
\left(\mathrm{mg} \mathrm{g}^{-1}\right)\end{array}$ \\
\hline \multirow[t]{3}{*}{0} & G. versiforme & $8.28 \mathrm{bc}$ & $36.37 a$ & $28.25 \mathrm{bc}$ & $0.25 b$ \\
\hline & G.mosseae & $9.27 \mathrm{ab}$ & $41.83 \mathrm{a}$ & $28.58 b c$ & $0.26 \mathrm{ab}$ \\
\hline & Non-AMF & $7.39 \mathrm{~cd}$ & $29.27 b$ & $24.22 \mathrm{~d}$ & $0.18 \mathrm{c}$ \\
\hline \multirow[t]{3}{*}{100} & G. versiforme & $6.43 \mathrm{~d}$ & $38.01 \mathrm{a}$ & $31.94 a$ & $0.27 \mathrm{ab}$ \\
\hline & G.mosseae & $7.54 \mathrm{~cd}$ & $35.82 \mathrm{a}$ & $30.93 \mathrm{ab}$ & $0.32 \mathrm{a}$ \\
\hline & Non-AMF & $10.63 \mathrm{a}$ & $21.63 \mathrm{c}$ & $25.89 \mathrm{~cd}$ & $0.19 \mathrm{c}$ \\
\hline \multicolumn{6}{|l|}{ ANOVA } \\
\hline Salt stress & & NS & * & ** & NS \\
\hline AMF & & $*$ & ** & ** & ** \\
\hline Interaction & & ** & NS & NS & NS \\
\hline
\end{tabular}

Note: Same letter within each column indicates no significant difference among treatments $(P<0.05)$. NS, no significant. ${ }^{*}, P<0.05 .{ }^{* *}, P<0.01$

\section{Discussion}

The present study here indicated that soil salinity significantly reduced the AM colonization. This is in agreement with the previous results (Kumar et al., 2010; Wu et al., 2010b). The AM colonization was always significantly higher in G. mosseae-colonized than in G. versiforme-colonized seedlings at both salinity levels, suggesting that $G$. mosseae possesses a more efficient potential for enhancing salt tolerance of citrus seedlings than G. versiforme.

It is well known that soil salinity obviously inhibits plant growth (Taffouo et al., 2010). The present results also indicated that, though the salt stress reduced the dry weights of the citrus seedlings, especially root and plant dry weights, the AMF seedlings exhibited significantly higher dry biomass as compared to non-AMF seedlings exposed to 0 and $100 \mathrm{mM} \mathrm{NaCl}$, implying that AMF can improve plant growth of salt-stressed citrus plants. Moreover, the significant differences were more obvious in $G$. mosseae-colonized seedlings. The results are in consonant with previous reported on C.tangerine (Wu et al., 2010b), Jatropha curcas (Kumar et al., 2010), Lactuca sativa (Jahromi et al., 2008) and Zea mays (Sheng et al., 2008).

Proline as a compatible osmoprotectant solute can protect cytosolic enzymes and cellular organelles, thus maintaining normal osmotic conditions (Jiménez-Bremont et al., 2006; Khedr et al., 2003). The proline concentrations here were notably higher in AMF than in non-AMF seedlings at both salinity levels, suggesting that exogenous AMF trigger internal proline accumulation to alleviate salt damage. The proline accumulation of the AMF seedlings may be due to the result that mycorrhizal seedlings recorded higher activity of a proline synthase, $\Delta^{1}$-pyrroline-5-carboxylate synthetase (Kavi Kishor et al., 1995). The present result is in agreement with the previous observation by Garg and Manchanda (2009), who reported that the quantum of an increase in synthesis and accumulation of proline was higher in mycorrhizal than in non-mycorrhizal Cajanus cajan plants subjected to salt stress. However, in another experiment, AMF trifoliate orange seedlings accumulated less proline concentration than non-AMF seedlings exposed to drought stress (Wu et al., 2007). These incompatible results suggest that the variation of the proline accumulation in the AMF trifoliate orange seedlings is dependent on stressed types.

Glucose, fructose and sucrose are preferred as the regulated substances responsible for osmotic adjustment in tissue water osmotic stress (Shatnawi et al., 2006). In the present work, the inoculated seedlings with AMF had higher concentrations of glucose and fructose when grown with 0 and $100 \mathrm{mM} \mathrm{NaCl}$. Under non-salinity stress, exogenous AMF increased sucrose concentrations of leaves, whereas under salinity stress these AMF markedly decreased sucrose concentrations. As the obligate symbionts, AMF must obtain a mount of their carbon (mainly hexose) from the hosts (Bago et al., 2003). Therefore, lower levels of sucrose in the salt-stressed seedling and higher levels of fructose and glucose in the present study imply that host sucroses transform more into hexose to support the symbiotic development and maintain normal water relations (Wu et al., 2010a). The phenomenon is more obvious under salinity stress. Compared to non-mycorrhization, the changed tendency of sucrose concentration due to mycorrhization was increased under non-salinity stress but decreased under salinity stress, adequately indicating that under salinity stress, mycorrhizal plants need more hexose to sustain the benefit effects on salt tolerance.

Osmotic adjustment involves not only organic solutes but also inorganic ions. The present study here observed that salt stress induced $\mathrm{Na}^{+}$and $\mathrm{Ca}^{2+}$ accumulation but decreased $\mathrm{K}^{+}$accumulation in both the AMF and non-AMF seedlings, which are in agreement with Al-Karaki (2000). On the other hand, AMF seedlings exhibited lower levels of $\mathrm{Na}^{+}$and $\mathrm{Ca}^{2+}$ but higher concentrations of $\mathrm{K}^{+}$, which would help the mycorrhizal seedlings to reduce cellular $\mathrm{Na}^{+}$accumulation to a toxic level, thus protecting host plants against salt damage. For the ratios of $\mathrm{K}^{+} / \mathrm{Na}^{+}, \mathrm{Ca}^{2+} /$ $\mathrm{Na}^{+}$and $\mathrm{Mg}^{2+} / \mathrm{Na}^{+}$, the inoculated seedlings had higher the values than the non-AMF control seedlings at both 
68

salinity levels, which are essential for normal cellular functions of mycorrhizal plants. The similar increases in $\mathrm{K}^{+} /$ $\mathrm{Na}^{+}$ratio of mycorrhizal Acacia nilotica, $\mathrm{Ca}^{2+} / \mathrm{Na}^{+}$ratio of mycorrhizal C. tangerine and $\mathrm{Mg}^{2+} / \mathrm{Na}^{+}$ratio of both mycorrhizal Sesbania aegyptiaca and S. grandiflora have also been reported previously (Giri and Mukerji, 2004; Giri et al., 2007; Wu and Zou, 2009).

\section{Conclusions}

From these results, it concluded that the salt stress inhibited trifoliate orange biomass, but the inhibition was alleviated by the exogenous AMF inoculation. Mycorrhizal colonization obviously improved the osmotic adjustment of the trifoliate orange seedlings at both salinity levels based on higher levels of organic solutes (sucrose, glucose, fructose and proline), higher $\mathrm{K}^{+}$concentration, higher ratios of $\mathrm{K}^{+} / \mathrm{Na}^{+}, \mathrm{Ca}^{2+} / \mathrm{Na}^{+}$and $\mathrm{Mg}^{2+} / \mathrm{Na}^{+}$, and lower $\mathrm{Na}^{+}$ level, thus alleviating partly salt damage.

\section{Acknowledgements}

The present work was supported by the Science-Technology Research Project of Hubei Provincial Department of Education (Q20111301) and the Open Funding of Key Laboratory of Ecological Agriculture of Ministry of Agriculture, People's Republic of China (2009k20).

\section{References}

Al-Karaki GN (2000). Growth of mycorrhizal tomato and mineral acquisition under salt stress. Mycorrhiza 10:51-54.

Bago B, Pfeffer PE, Abubaker J, Jun J, Allen JW, Brouillette J, Douds DD, Lammers PJ, Shachar-Hill Y (2003). Carbon export from arbuscular mycorrhizal roots involves the translocation of carbohydrate as well as lipid. Plant Physiol 131:1496-1507.

Chaves MM, Flexas J, Pinheiro C (2009). Photosynthesis under drought and salt stress: regulation mechanisms from whole plant to cell. Ann Bot 103:551-560.

Chinnusamy V, Jagendorf A, Zhu J-K (2005). Understanding and improving salt tolerance in plants. Crop Sci 45:437448 .

de Lacerda CF, Cambraia J, Oliva MA, Ruiz HA (2003). Osmotic adjustment in roots and leaves of two sorghum genotypes under $\mathrm{NaCl}$ stress. Braz J Plant Physiol 15:113118.

Duke ER, Johnson CR, Koch KE (1986). Accumulation of phosphorus, dry matter and betaine during $\mathrm{NaCl}$ stress of split-root citrus seedlings colonized with vesiculararbuscular mycorrhizal fungi on zero, one or two halves. New Phytol 104:583-590.

Evelin H, Kapoor R, Giri B (2009). Arbuscular mycorrhizal fungi in alleviation of salt stress: a review. Ann Bot 104:12631280.

Feng G, Zhang FS, Li XL, Tian CY, Tang C, Rengel Z (2002).
Improved tolerance of maize plants to salt stress by arbuscular mycorrhiza is related to higher accumulation of soluble sugars in roots. Mycorrhiza 12:185-190.

Ferreira AL, Lima-Costa ME (2008). Growth and ultrastructural characteristics of Citrus cells grown in medium containing $\mathrm{NaCl}$. Biol Plant 52:129-132.

Garg N, Manchanda G (2009). Role of arbuscular mycorrhizae in the alleviation of ionic, osmotic and oxidative stresses induced by salinity in Cajanus cajan (L.) Millsp. J Agron Crop Sci 195:110-126.

Giri B, Kapoor R, Mukerji KG (2007). Improved tolerance of Acacia nilotica to salt stress by arbuscular mycorrhiza, Glomus fasciculatum may be partly related to elevated K/Na ratios in root and shoot tissues. Microb Ecol 54:753-760.

Giri B, Mukerji KG (2004). Mycorrhizal inoculant alleviates salt stress in Sesbania aegyptiaca and Sesbania grandiflora under field conditions: evidence for reduced sodium and improved magnesium uptake. Mycorrhiza 14:307-312.

Graham JH, Syvertsen JP (1989). Vesicular-arbuscular mycorrhizas increase chloride concentration in citrus seedlings. New Phytol 113:29-36.

Hajlaoui H, El Ayeb N, Garrec JP, Denden M (2010). Differential effects of salt stress on osmotic adjustment and solutes allocation on the basis of root and leaf tissue senescence of two silage maize (Zea mays L.) varieties. Ind Crop Product 31:122-130.

Jahromi F, Aroca R, Porcel R, Ruiz-Lozano JM (2008). Influence of salinity on the in vitro development of Glomus intraradices and on the in vivo physiological and molecular responses of mycorrhizal lettuce plants. Microb Ecol 55:45-53.

Jiménez-Bremont JF, Becerra-Flora A, Hernández-Lucero E, Rodríguez-Kessler M, Acosta-Gallegos JA, RamírezPimentel JG (2006). Proline accumulation in two bean cultivars under salt stress and the effect of prolines and ornithine. Biol Plant 50:763-766.

Kavi Kishor PB, Hong Z, Miao GH, Hu CAA, Verma DPS (1995). Overexpression of $\Delta^{1}$-pyrroline-5-carboxylate synthetase increase proline production and confers osmotolerance in transgenic plants. Plant Physiol 108:13871394.

Khedr AHA, Abdel Wahid AA, Paul Quick W, Abogadallah GM (2003). Proline induces the expression of salt-stressresponsive proteins and may improve the adaption of Pancratium maritimum L. to salt-stress. J Exp Bot 54:25532562.

Kumar A, Sharma S, Mishra S (2010). Influence of arbuscular mycorrhizal (AM) fungi and salinity on seedlings growth, solute accumulation, and mycorrhizal dependency of Jatropha curcas L. J Plant Growth Regul 29:297-306.

Levy Y, Syvertsen J (2004). Irrigation water quality and salinity effects in citrus trees. Hortic Rev 30:37-82.

Murkute AA, Sharma S, Singh SK (2006). Studies on salt stress tolerance of citrus rootstock genotypes with arbuscular mycorrhizal fungi. Hortic Sci 33:70-76. 
Pérez-Pérez JG, Robles JM, Tovar JC, Botia P (2009). Response to drought and salt stress of lemon 'Fino 49' under field conditions: water relations, osmotic adjustment and gas exchange. Sci Hortic 122:83-90.

Pérez-Tornero O, Tallon CI, Porras I, Navarro JM (2009). Physiological and growth changes in micropropagated Citrus macrophylla explants due to salinity. J Plant Physiol 166:1923-1933.

Phillips JM, Hayman DS (1970). Improved produces for clearing roots and staining parasitic and vesicular-arbuscular mycorrhizal fungi for rapid assessment of infection. Trans $\mathrm{Br}$ Mycol Soc 55:158-161.

Reed RH (1989). Osmotic adjustment and organic solute accumulation in Chaetomorpha capillaris. Br Phycol J 24:2137.

Requena N, Serrano E, Ocón A, Breuninger M (2007). Plant signals and fungal perception during arbuscular mycorrhiza establishment. Phytochem 68:33-40.

Sairam RK, Tyagi A (2004). Physiology and molecular biology of salinity stress tolerance in plants. Curr Sci 86:407-421.

Shatnawi MA, Shibli RA, Migdadi H, Obeidat A, Ereifej K, M-Abu-Ein A (2006). Influence of different carbon sources on wild pear (Pyrus syriaca) growth and sugar uptake. World J Agric Sci 2:156-161.

Sheng M, Tang M, Chen H, Yang B, Zhang F, Huang Y (2008). Influence of arbuscular mycorrhizae on photosynthesis and water status of maize plants under salt stress. Mycorrhiza 18:287-296.

Silveira JAG, Araújo SAM, Lima JPMS, Viégas RA (2009). Roots and leaves display contrasting osmotic adjustment mechanisms in response to $\mathrm{NaCl}$-salinity in Atriplex nummularia. Environ Exp Bot 66:1-8.
Taffouo VD, Nouck AH, Dibong SD, Amougou A (2010). Effects of salinity stress on seedlings growth, mineral nutrients and total chlorophyll of some tomato (Lycopersicum esculentum L.) cultivars. Afr J Biotechnol 9:5366-5372.

Troll W, Lindsely J (1955). A photometric method for the determination of proline. J Biol Chem 215:655-660.

Wu QS, Peng YH, Zou YN, Liu CY (2010a). Exogenous polyamines affect mycorrhizal development of Glomus mosseae-colonized citrus (Citrus tangerine) seedlings. ScienceAsia 36:254-258.

Wu QS, Xia RX (2006). Arbuscular mycorrhizal fungi influence growth, osmotic adjustment and photosynthesis of citrus under well-watered and water stress conditions. J Plant Physiol 163:417-425.

Wu QS, Xia RX, Zou YN (2008). Improved soil structure and citrus growth after inoculation with three arbuscular mycorrhizal fungi under drought stress. Eur J Soil Biol 44:122-128.

Wu QS, Xia RX, Zou YN, Wang GY (2007). Osmotic solute responses of mycorrhizal citrus (Poncirus trifoliata) seedlings to drought stress. Acta Physiol Plant 29:543-549.

Wu QS, Zou YN (2009). Arbuscular mycorrhizal symbiosis improves growth and root nutrient status of citrus subjected to salt stress. ScienceAsia 35:388-391.

Wu QS, Zou YN, He XH (2010b). Contributions of arbuscular mycorrhizal fungi to growth, photosynthesis, root morphology and ionic balance of citrus seedlings under salt stress. Acta Physiol Plant 32:297-304. 